\title{
Speed-controlled Hydraulic Drive Systems for Heavy Machinery
}

\author{
Darko Lovrec ${ }^{1 *}$, Vito Tič ${ }^{1}$ \\ ${ }^{1}$ Faculty of Mechanical Engineering, University of Maribor, Maribor (Slovenia)
}

The paper discusses electrohydraulic variable supply systems in different design concepts. In the forefront of discussion are design concepts with constant and speed-controlled electric motor in combination with constant and variable pumps, implemented within different control strategies.

\section{Keywords: Hydraulic supply system, Variable pump flow, Control concepts}

\section{INTRODUCTION}

Reductions in energy consumption and noise reduction regarding drive systems, as well as costeffectiveness, are increasingly important factors in modern machinery design. All of the above requirements are especially important for machines equipped with hydraulic supply and drive systems. Application areas are heavy tool and metal shaping and forming machines, presses, and extruders, machines in the steel processing industry and all machines with a large installed power in many other areas. In some applications, rational energy use is more important than drive dynamics, while in other cases it is important to both. [1], [2]

Adapting to the energy needs of the actuator, to the current load of the actuator or actuators, can be achieved with an adaptive hydraulic power supply system and an appropriate strategy for adjusting the power of the hydraulic actuator or actuators. For example, the LoadSensing, LS system, has long been known as one such system, as well as the Flow-Matching system and many other variants, which represent larger or smaller upgrades of these and similar systems of this kind. What these systems have in common is that adjustable, variable hydraulic pump flow is used to adapt to the needs of the actuators - volumetrically pump control. Only the principle of volumetrically-controlled hydraulic energy (variable supply systems e.g. with the use of variable pumps), has proved satisfactory for the above requirements and solutions. In some cases, adaptation can be achieved with both hydraulic-mechanical and electrohydraulic variant of the pump control, whereby the latter variant providing a number of additional advantages, especially in terms of the use of appropriate adaptive control concepts - electro-hydraulic adaptive control concepts. In this regard, electro-hydraulic solutions in particular, make it possible to use all the advantages of modern electrical signal transmission and controller designs. [3], [4], [5], [6]

In the electro-hydraulic version hydraulic variable supply systems of the pump control can be, in principle, controlled on hydraulically (pump control) or electrically (electric motor control) site. Constant-speed electric motors in combination with a variable displacement volume pump are commonly used solutions, in order to control flow, or consequently, the pressure of the fluid. The second concept represents the drive design using a constant displacement volume pump in combination with variable rotational speed electric motor. The latter concept is extremely interesting in praxis due to the affordable price and robustness of the complete drive. This is especially true in cases where a conventional, speedcontrolled asynchronous electric motor and a suitable gear pump are used to perform the drive. In the third case, a speed-controlled hydraulic variable pump can be used. [7], [8], [9], [10]

All three mentioned examples of variable drive design concept: variable pump and constant electric motor (hydraulic pump variable system), constant pump and variable speed electric motor drive (electric variable hydraulic system) as well as variable pump and variable speed electric motor drive (electric and hydraulic variable system), are shown schematically in Table 1.

Table 1: Different electrohydraulic variable drive concepts

\begin{tabular}{|c|c|c|c|}
\hline & Design concept CV & $\begin{array}{c}\text { Design concept VC } \\
\text { Variable frequency drive } \\
\text { controller } \\
\text { Asynchronous motor } \\
\text { Constant gear pump }\end{array}$ & $\begin{array}{c}\text { Design concept VV } \\
\text { Variable frequency drive } \\
\text { controller } \\
\text { Asynchronous motor } \\
\text { Variable axial piston pump }\end{array}$ \\
\hline Pump's rotational speed & $\underline{\text { Constant }}$ & $\underline{\text { Variable }}$ & $\underline{\text { Variable }}$ \\
\hline Pump's displacement & $\underline{\text { Variable }}$ & $\underline{\text { Constant }}$ & $\underline{\underline{\text { Variable }}}$ \\
\hline Scheme & M & &
\end{tabular}

${ }^{*}$ Corresponding author: University of Maribor, Faculty of Mechanical Engineering, Smetanova ulica 17, Maribor, Slovenia; darko.lovrec@um.si

${ }^{*}$ Article presented at the conference in the oral form, HM2021, Vrnjačka Banja 
The paper discusses in more detail two design concepts for speed-controlled hydraulic drives. In the first case, a simpler example of a speed-controlled constant hydraulic pump is presented, using a cost-effective frequency-controlled asynchronous electric motor. A press-brake machine served as an example of the application of this concept. In the second case, the concept of a speed-controlled variable pump is presented. This concept involves the simultaneous control of the rotational speed of the drive electric motor combined with simultaneously adjusting the variable axial piston pump. This concept of cascade-control, with two controllers, enables the control of the drive with the highest efficiency, at the same time with higher dynamics.

\section{VARIABLE PUMP FLOW WITH CONSTANT PUMP}

The use of a constant pump driven by a speedcontrolled asynchronous electric motor is one of the most cost-effective variants. In the case of a robust gear pump with internal gears, the entire design is additionally very robust and less sensitive to solid contaminants in hydraulic fluids. Using a low noise gear pump (so-called silence pump), the noise level of the hydraulic drive is lower.

In a variant with a speed controlled asynchronous electric motor and the constant pump, the question often arises about the dynamics of the drive and its efficiency. "What are the characteristic properties and comparative advantages or disadvantages of this concept, particularly in regard to dynamic behaviour?" and "Is it possible to replace an existing hydraulic supply system powered by a hydraulic-mechanically controlled variable pump, with a speed-controlled constant pump?" The main concern is the high inertia of electro motors' rotational parts, compared to the swash-plate of a variable pump.

In order to answer the above questions, the real application of an industrial press-brake was considered, which is used for cast product finishing in the automotive industry. Part of the hydraulic scheme of the discussed hydraulic press brake with its existing hydraulicmechanically controlled axial piston pump needing to be replaced with speed controlled constant pump, is shown in Figure 1 (for more details see [4]).

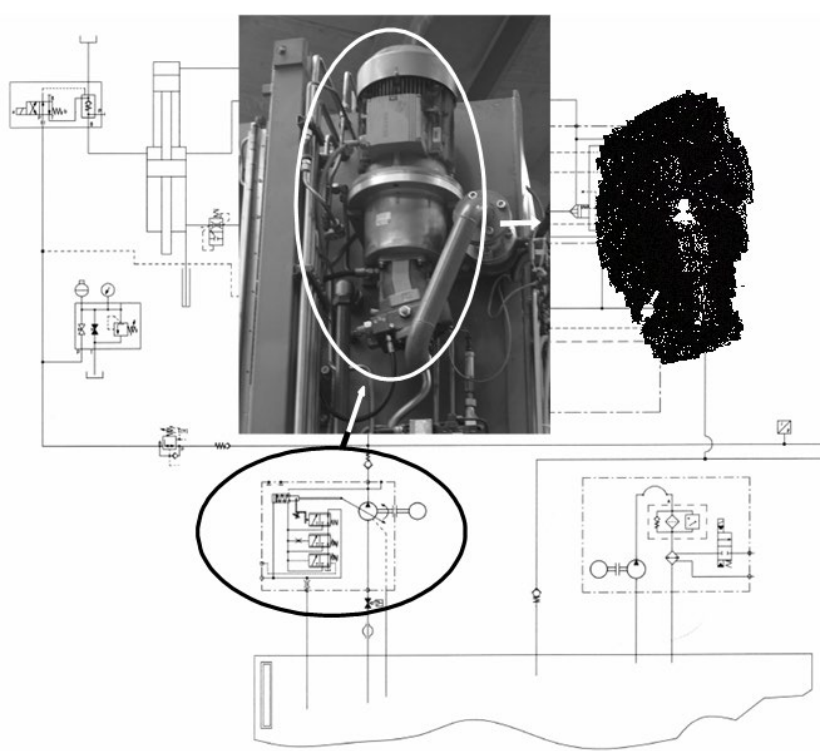

Figure 1: Hydraulic press brake with a variable pump replaced with a speed controlled constant pump

Each machine has its own working cycle - the duration of each working phase and the dynamics of speed changes between phases. In the case of replacing one type of drive with another, special care must be taken to ensure the same dynamics. This is even more important in the case of speed control with an electric motor, which is characterized by a large inertia mass of the rotor.

For the purpose of using a different drive concept, it is therefore first necessary to check the drive dynamics: to know the exactly profile of the working cycle. In the next step, it makes sense to build a test facility where we can practically check the dynamics of the new drive concept and give a statement on the suitability of the drive.

In order to carry-out the intended drive replacement, it was necessary to establish a real workingprofile of the machine and its pressure characteristics over the whole working cycle and adapt it for testing purposes. The actual course of pressure changes in regard to more dynamically demanding machining is presented in Figure 2. It was used as a starting point for further studies.

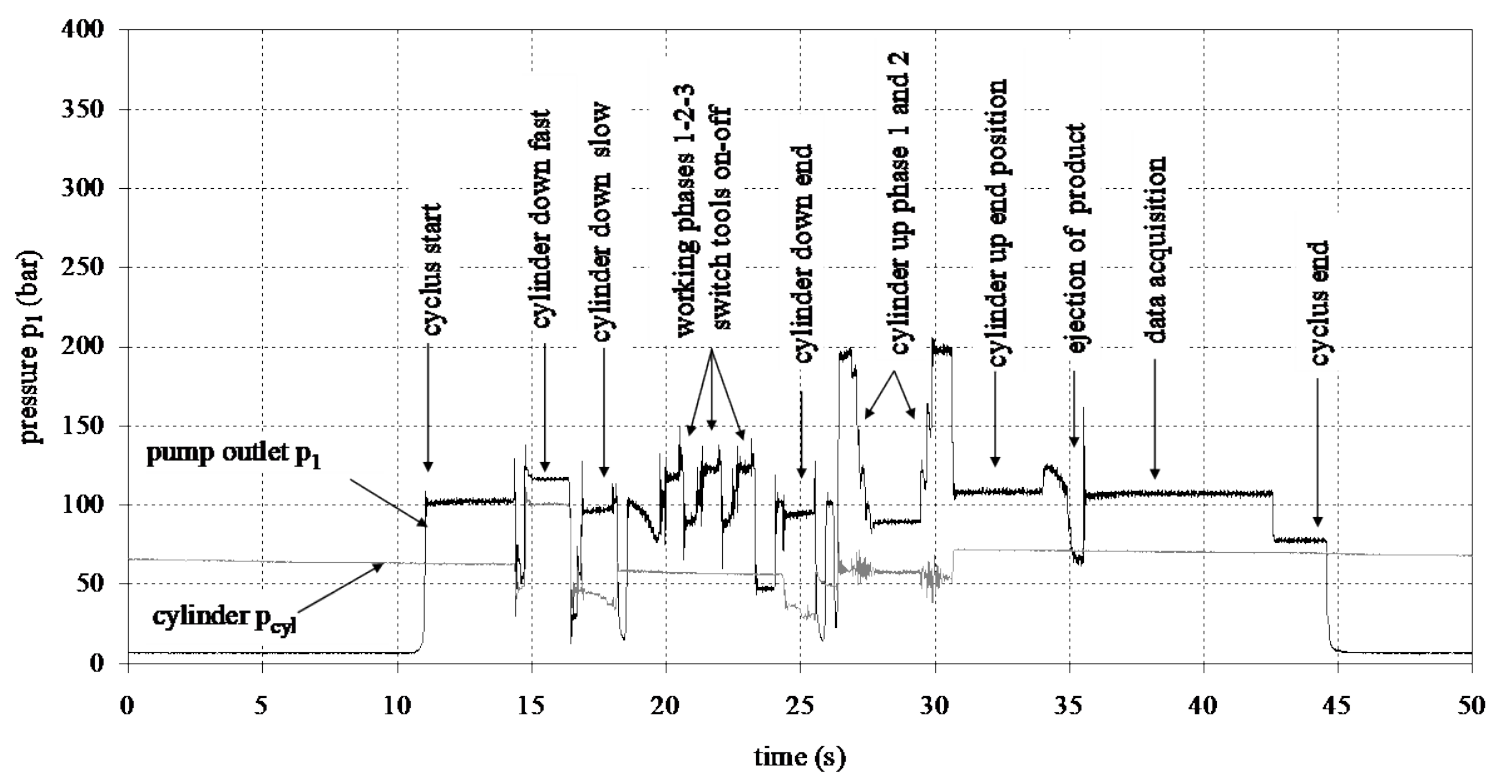


Figure 2: Real pressure profile over the working cycle with working phases

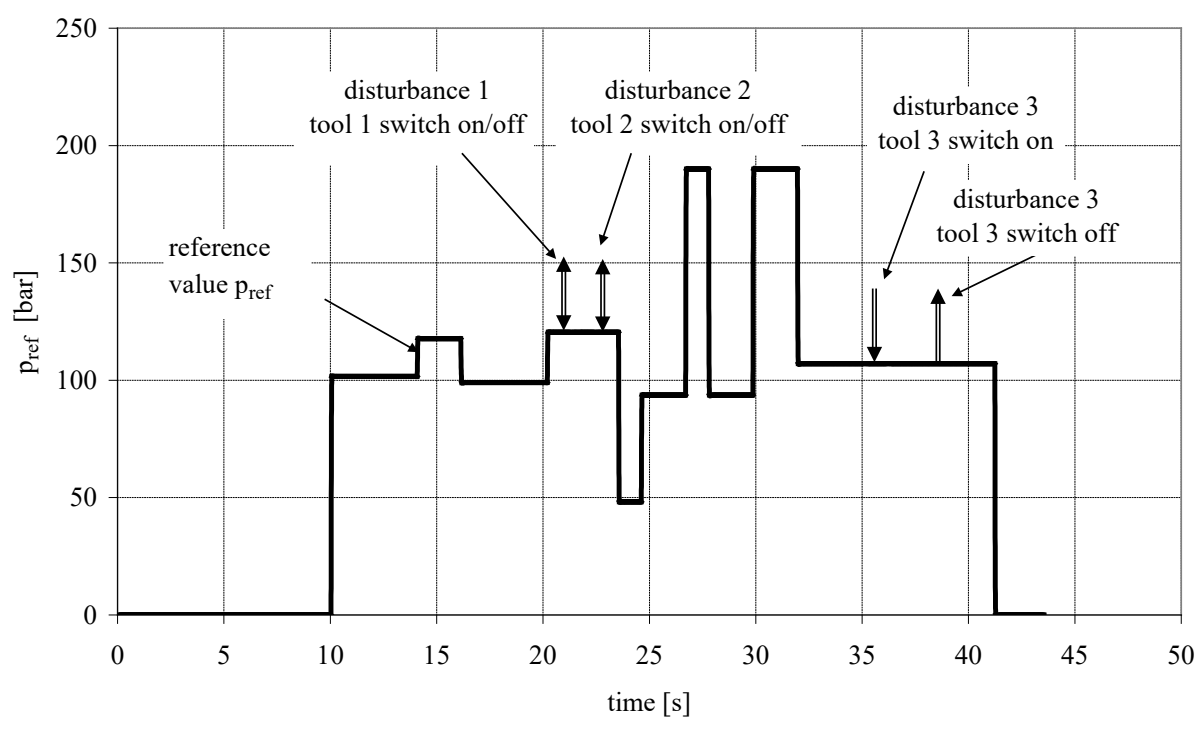

Figure 3: Adapted pressure profile for testing purposes

An adapted, but dynamically comparable pressure profile was generated, to be achieved by using a speedcontrolled constant pump in load-sensing control concept. The adapted profile is presented in Figure 3.

\subsection{Testing the speed-controlled constant pumps concept}

In the first step, it was necessary to determine the difference in the dynamics of the response in the pressure control, performed once with a conventional variable pump and a second time with a speed-controlled constant pump. For this purpose and for the purposes of further research, a multi-purpose test facility was built, as shown in Figure 4. The drive capacity of the existing power unit was considered. A selection of those components to be used on the suggested drive concept was introduced for the testrig. Cost-effective industrial components, available on the market, were used intentionally to build the rig.

A commonly used variable axial piston swash-plate pump (A10VSO NG30, Bosch-Rexroth), driven by a $15 \mathrm{~kW}$ asynchronous electric motor was used for the variable pump principle. Due to the constant drive speed $\left(1500 \mathrm{~min}^{-1}\right)$ the flow depends solely on the pump swashplate angle. Control of the swash plate system is done by a proportional valve. The swash-plate control system is internally supplied from the pressure control pipeline system. Consequently, additional disturbance is introduced, but no additional supply system is needed.

For the concept of speed-controlled constant pump, axial piston pump was replaced by a constant internal gear pump (PGF3 31/032RE07VE4, Bosch-Rexroth) driven by the same $15 \mathrm{~kW}$, but now speed-controlled asynchronous electric motor. The electric motor is driven by a frequency converter (Midimaster vector 6SE32, Siemens). The pump supplies a hydraulic pipeline system of equivalent length and dimensions (comparable hydraulic capacity and inductivity [4]), and corresponds to the existing pipeline systems of the press-brake, or different design variant (variation of pipeline lengths).

Overloading of the system is prevented by an additional pressure relief-valve. The remaining components of the test-rig are the loading unit, pressure sensors, and the control and signal acquisition system.

The loading unit consists of two throttle valves $\mathrm{TV}_{1}$ and $\mathrm{TV}_{2}$ which, used together with a proportional pressure valve, make-up the load - hydraulic cylinder of the press. The components of the loading units enable realistic simulation of the real system's workloads. Disturbances of the control, such as switching on/off the additional actuators, was simulated by a directional-valve mounted in front of the throttle valve $\mathrm{TV}_{2}$, enabling an almost instant change in the hydraulic flow.

Two additional pressure sensors were applied at the pump outlet port $\left(p_{1}\right)$, and at the end of the pipeline system $\left(p_{2}\right)$, for pressure variation acquisition.

All the devices needed for control of the constant pump and variable-speed electric motor (setting of control structure, controllers...) were integrated into the frequency converter. The setting of reference values, data acquisition, monitoring, and graphical interfacing were performed using a personal computer.

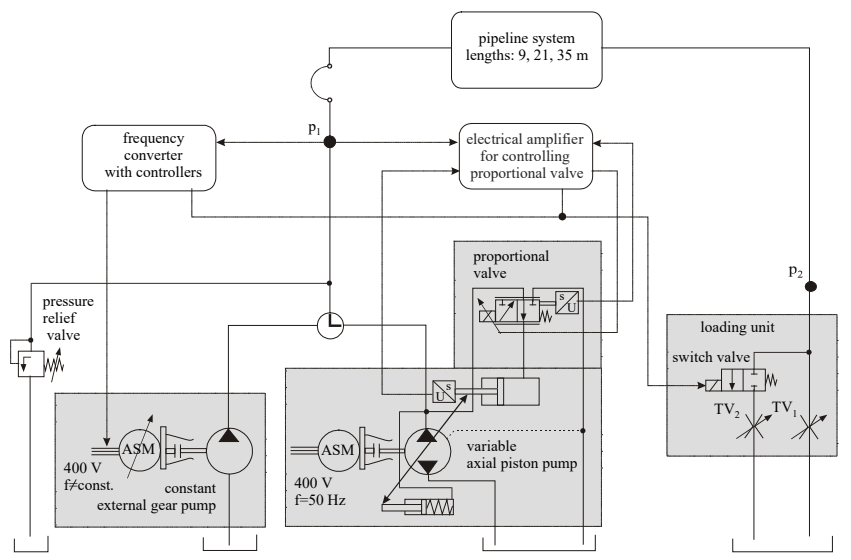

Figure 4: Structure of the test-rig

\subsection{Features of both control concept}

The conceptual design of such complex systems, including the interference of hydraulics, electronics, control techniques and sensor technology is a very 
demanding task. Application of a suitable block scheme can be a very helpful tool.

The special features of both concepts must be considered in order to understand and clearly describe the actual state and, consequently, specific behavior of the discussed control systems. [4]

For instance, in the case of the variable pump, it is reasonable to consider a specific type of supplying swash-plate system. An internally supplied 3/2proportional control valve was used in our case. Such a design solution is simpler than a valve with additional external supply, but has certain disadvantages: any change in the disturbance value or reference values, influences the control loop's properties. A variable amount of fluid needed for internal valve supply is taken from the controlled pipeline system, with the additional influence of the current pressure level. Consequently, inferior dynamic and static performance can be expected.

The principal simple block scheme of pressure control with a variable pump within a single control loop, and including the above specific features as used on our test rig, is presented in Figure 5 above.

When constant pump and speed-controlled asynchronous motor are used for pressure (or for flow as well as power) control, there are two active control loops: the speed control loop of the asynchronous motor as a secondary (internal) control loop, and the pressure control as a primary control loop. Such a solution is known as cascade-control [13].

In the case of cascade-control, two variables, pressure $p$ and electric motor turning speed $n$ are monitored. Both values are measured and controlled. A principal block diagram of pressure control in the case of a constant pump is shown in Figure 5, below. The control system structure is typical example of cascade-control.

In the case of cascade-control, special attention should be paid to choosing an appropriate type of controller (see e.g. [13]). It is important to ensure that the selected secondary controller provides sufficient control loop dynamics, which must be as fast and stable as possible, over whole the expected operating range. The primary controller must allow for optimal pressure control behaviour. In the case under consideration, a P-controller was used in the secondary loop, and a PID-controller was used in the primary control-loop. When both secondary and primary controllers are applied, more appropriate dynamic behaviour can be expected. The application of a secondary controller allows for faster disturbance handlings in the secondary loop.
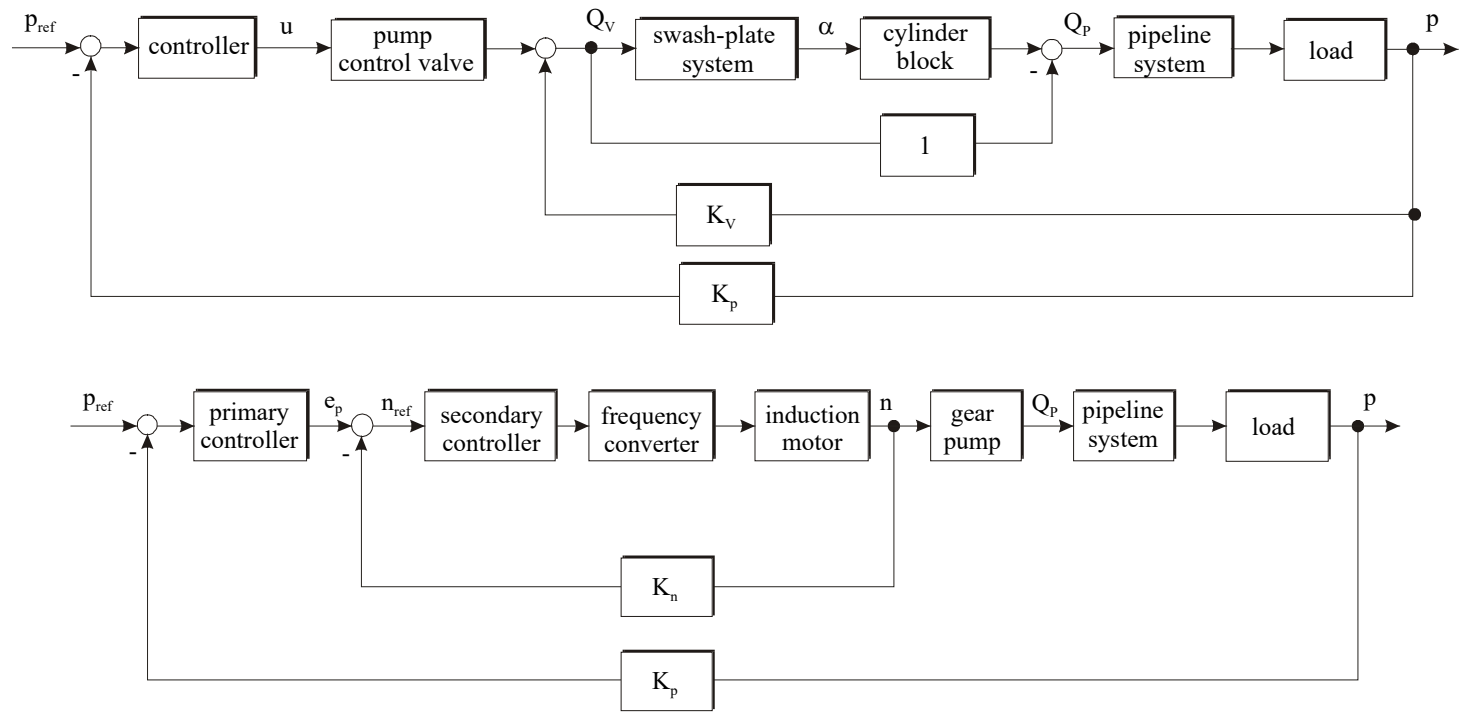

Figure 5: Principal block diagram of discussed control concepts; with a variable pump (above) and constant pump (below)

For the testing purposes regarding the dynamic behaviour of both pressure control concepts a principal pressure profile of the combined reference-disturbance behaviour, for the equal pipeline length, was designed Figure 6. The assumed ratio of dynamic responses corresponds to the ratio of inertia of the electric motor's rotational parts, compared to the swash-plate of the variable pump. Consequently, due to a higher electric motor, the inertia speed-controlled concept is expected to react more slowly.

The reference behaviour of the control (following the prescribed reference pressure profile) is presented by a step change of the reference value up to 140 bars. The disturbance behaviour is afterwards simulated by switching the additional load (throttle valve $\mathrm{TV}_{2}$ ) on/off. Throttle valves are adjusted in such manner that at the working point $\mathrm{OP}_{1}$ the pump flow tilts in order to deliver $35 \%$ of maximum flow and approximately $70 \%$ in $\mathrm{OP}_{2}$.

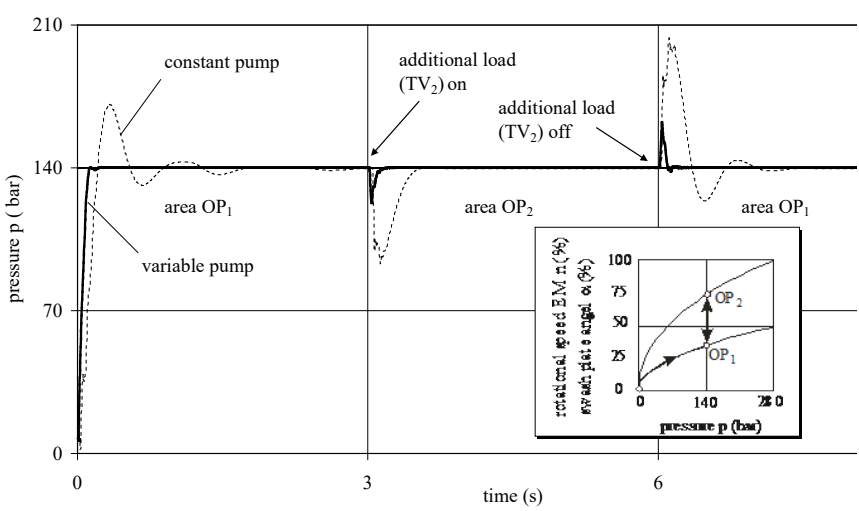

Figure 6: Expected responses to the reference and disturbance steps for both drive concepts 
Rapidly opening of the throttle valve causes a substantial drop in pressure. Consequently, fluid flow changes according to the component's characteristics. Due to control error, the swash-plate angle is increased, in the case of speed-controlled motor, and turning speed is increased, respectively. Until the flow through the throttle valves is higher than the pump flow, the pressure decreases. In order to sustain the required pressure, the pump must replace the missing volume. The swash-plate angle, or electric motor turning speed, respectively, increases until the pressure exceeds the required value. When the required pressure is reached, both the increasing values remain fixed. Analogous, but inverse behaviour is present when closing the same throttle valve.

It is necessary to perform both control concepts under equal conditions: the same operating conditions, same change of operational points, same pipeline lengths and same loads.

A satisfactory answer to the question: "What is the actual difference between the dynamic responses of both pressure control concepts?" can only be obtained by experimental comparison of both. A comparison of the concepts is shown here only for the case of a $33 \mathrm{~m}$ long pipeline and for equal control requirements.

The main objective of the control was to achieve a quality pressure profile as a controlled quantity, regarding reference and disturbance actions: small or no steady state errors, acceptable overshoot, appropriate dynamics and a short-time of disturbance compensation. The control responses achieved by the variable and constant pump are presented in Figure 7.

The Figure 7 shows the dynamic responses to typical steps in the reference value achieved with the variable pump in a test the configurations for $33 \mathrm{~m}$ long pipeline. Any influence on the operating points and corresponding pressure losses can be noticed. The pressure losses (difference between $p_{1}$ and $p_{2}$ ) are due to a relatively smaller pump flow in $\mathrm{OP}_{1}$ (see value of the swash-plate angle $\alpha$ ) smaller than in $\mathrm{OP}_{2}$.
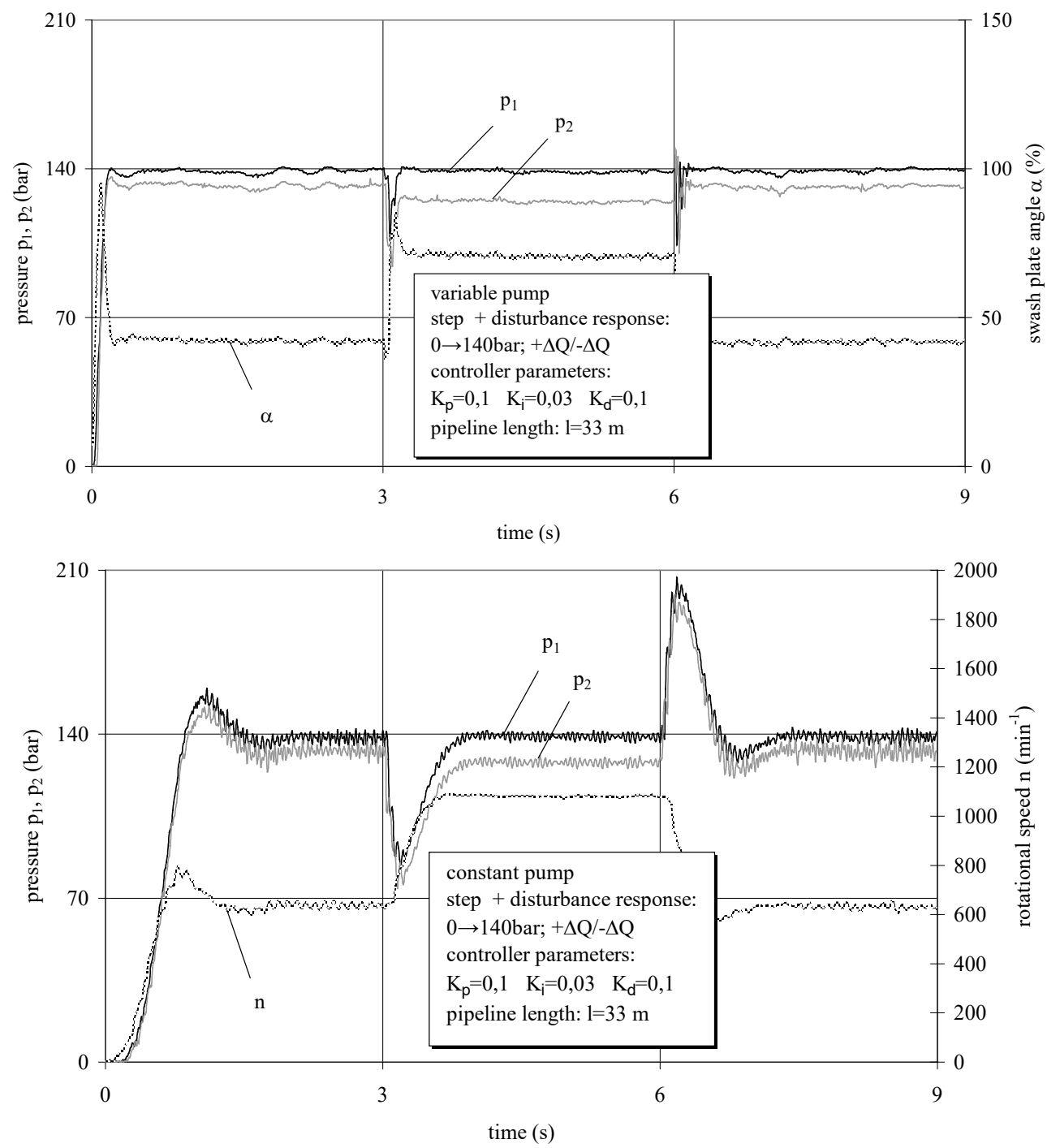

Figure 7: Experiment; pressure, rotational speed and power distribution in the case of a variable pump (above) and a speed-controlled constant pump (below)

Comparison of the dynamics regarding the reference behavior of pressure between variable and constant pump concepts gives the ratio $1: 4.7$. In the case of disturbance behavior when switching on the load, the obtained ration is approximately $1: 3$ and by switching the load off $1: 4.4$. Based on the obtained experimental results, the general ratio of dynamic responses (variable pump versus constant pump principle) can be estimated at 
between $1: 4$ and $1: 5$. In other words, the variable pump control, $\mathrm{CV}$-concept responds 4 to 5 times faster than the constant pump VC-concept, in spite of the much higher rotating masses inertia ratio (swash-plate versus electric motor rotor).

Besides the known dynamic ratio of both compared control concepts, it is reasonable to consider some other features like the necessity of pressure signal conditioning, choice of appropriate electric motor and frequency converter to be applied in hydraulic systems and, nevertheless, to choose an appropriate constant pump and to be familiar with the operational regime that is to be applied in such a concept. This complex and interdisciplinary know-how is needed to assure faultless and maintenance-free operation.

In the case of constant pump VC-concept, much higher-pressure pulsation can be noticed than in the case of the variable pump. Such behavior can be ascribed to the applied signal conditioning.

In the case of variable pump flow and, consequently, pressure pulsation corresponds to the turning speed, the number of pump pistons, and is constant. Signal filtering can be set regarding the above known frequency. This is not the case when pressure control is realized with a constant pump and variable electric motor turning speed. Frequency changes according to the value of the product: number of gear teeth times turning speed.

In the case with speed-controlled pump, it is possible to filter the controlled value with a filter of constant settings, whereas it is inapplicable in the second case. An adaptive filter (see e.g. [14]) should be used or a turning speed (operating point) should be chosen, where the signal filtering is optimal. Consequently, signal filtering will not be optimal at every other turning speed. The latter type of filtering was applied in order to preserve a simple design for the suggested control concept. Consequently, it results in higher pulsation of the pressure at every non-optimal rotation speed, and a corresponding influence on the control of the electric motor's rotation speed. For more information regarding pressure control with both concepts and different influencing factors, modelling the system is given in the literature [12], [13], [15], [16].

\subsection{Load-sensing pressure control concept}

In our case, the implementation of a speedcontrolled constant pump, the pressure control was performed according to the load-sensing (LS) control concept. When supplying a number of independent valvecontrolled actuators with different loads and with a single pump, in the load-sensing concept, the supply pressure is adjusted to suit the actuator's highest-pressure value.

In a load-sensing concept, the supply pressure is variable. It changes to accommodate the highest load pressure. It lies at a value $\Delta p_{\text {LS }}$ above the highest load pressure. When the LS-system with variable pump is used, the pressure and flow dependent losses are reduced. Pressure is measured at the most loaded actuator $p_{2}$, (see Figure 4), while the pump is controlled according to the pressure increased by a certain $\Delta p_{\text {LS }}$ (actual pump control pressure is: $p_{2}+\Delta p_{\mathrm{LS}}$ ), needed to cover the losses in a hydraulic pipeline system. The use of a variable displacement pump in a load-sensing operation presents the most economical energy supply type for several valve-controlled actuators (for more details see [12]).

LS-control concept is, in fact, a pressure control approach where the controlled value is not 'given from outside' but generated inside the controlled system, depending on the actual load. The required pressure level corresponds to the current level of load increased for the value of the pressure difference due to the load $\Delta p_{\text {LS. To }}$ reduce power losses, $\Delta p_{\mathrm{LS}}$ should be as small as possible, then again big enough to ensure the expected dynamic.

In the following, the LS-pressure control concept using a variable speed motor and constant pump was tested experimentally for a previously presented operational profile of a metal forming machine. Such a strategy was chosen due to the fact that the hydraulic cylinder of the press for most of the working cycle operates as the most loaded actuator with variable load (except in the initial and final phases during product manipulation - see Figure 2). Above all, the main purpose of the presented work was to check the feasibility of the LS-control concept with a variable speed motor and constant pump in the case of a real operational profile for metal-forming machine.

Application of such concept was motivated by scepticism regarding the dynamic properties of control systems using variable pumps with higher inertia of rotational parts. It could be even slower in combination with the LS-control concept where the controlled value is generated inside the controlled system.

The existing controllers in the used frequency converter were used for realization of cascade-control. It was necessary to configure the control structure and set appropriate controller parameters, to meet the requirements of the described cascade control. Definition and optimisation of both controllers was carried out, in accordance with the principles of the control technique: always in a stable and optimally steady-state, and with dynamic behaviour. The above-mentioned necessary tasks were also done in compliance with the manufacturer's instructions for the applied frequency converter.

A PI-controller was used, as a secondary controller, to control speed, whereas the integral parameter was set as low as possible (to achieve behaviour similar to the suggested simple P-controller). A PID-controller was used, as primary controller, to control the pressure, whereas a higher integral parameter was set to achieve pressure control without steady-state error.

An actual profile of the achieved control-values, using the suggested LS-control concept, is shown in Figure 8. The actual profile is in accordance with a simplified pressure profile as shown in Figure 3. The variable flow of the constant pump and power is presented, in addition to the pump pressure profile. The latter two profiles were calculated from the actual turning speed and geometrical volume of the pump, regarding the influence of compressibility and temperature of the media.

The pressure, rotational speed and calculated power of the driven electrical motor are achieved using load-sensing reference value $\Delta p_{\mathrm{LS} \text {,ref }}=10$ bar. As mentioned, before it must be sufficient to cover all pressure losses in the system and to enable expected dynamics. 


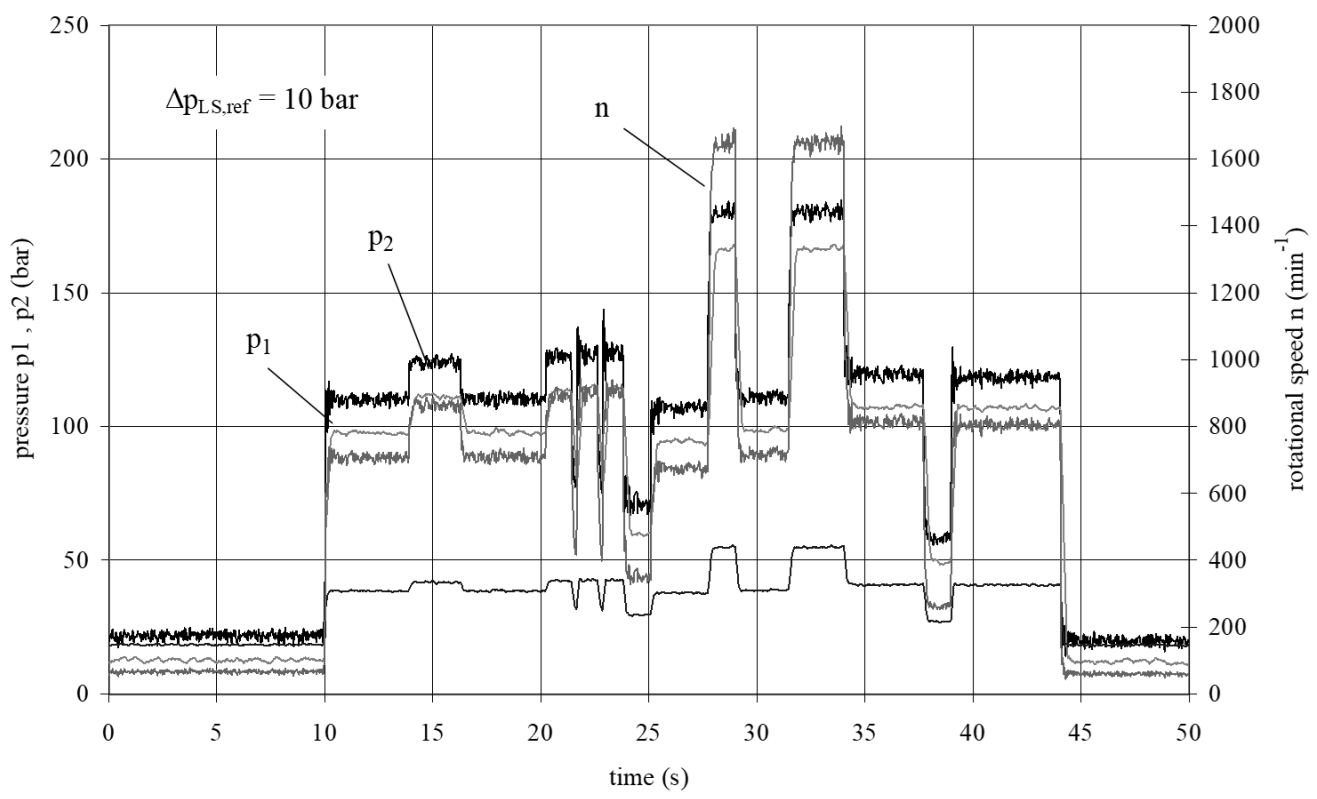

Figure 8: Experiment; pressure, rotational speed and power distribution in the case of a speed-controlled motor and internal gear pump $\Delta p_{L S, \text { ref }}=10$ bar

As it can be seen from Figure $8, \Delta p_{\mathrm{LS}, \text { ref }}=10$ bar enables suitable dynamics of the actuator $p_{\text {load }}=p_{2}-$ press cylinder to follow pressure changes during the working cycle.

Choosing a suitable $\Delta p_{\mathrm{LS} \text {,ref }}$ is very important for achieving adequate dynamics. This system will provide very good control dynamics if too high a value is selected, but will operate at higher pressure than needed. Consequently energy consumption and power losses will be increased. In the case of $\Delta p_{\mathrm{LS} \text {,ref }}$ set too low (e.g. $\Delta p_{\text {LS,ref }}=6$ bar), power losses will decrease but it will be impossible to achieve the required control dynamics. To satisfy general power-loss reduction efforts, it certainly must be taken into account. [4]

As can be seen from the experimental results, the suggested LS-control concept using variable speed motor and constant pump enables low energy losses and reasonably priced solutions. It can be used for metal forming machines, despite some doubt regarding dynamics.

\section{VARIABLE PUMP FLOW WITH SPEED CONTROLLED VARIABLE PUMP}

The fact is, that the most machines are still using the classic drive concept: A constant volume pump or, as a better solution, the usage of a variant variable displacement pump, in both cases driven at constant speed. The requirement for greater robustness, taking into account the reasonable price, has led to usage of the speed controlled constant pumps. However, such a concept cannot meet the dynamic requirements of the classic drive concept.

The more effective approach, to adapt the supply energy to the actual needs of the actuator(s) or load, offers the combination of a variable pump and a speed-controlled electric motor. Within this drive concept, two parameters need to be adjusted: The rotational speed of the electric motor and the displacement volume of the used variable pump as well. All three mentioned adaptive supply principles with main properties are shown in Table 1.

More information regarding the detailed drive design, including the specified type and characteristics of used components, along with its efficiency, reliability, robustness, operating costs, purchase price, has been the subject of various researches e.g. [17] - [22]. The same applies to studies related to the use of a wide range of control concepts and control strategies, from classical to non-linear approaches that have proven to be effective on hydraulic or other types of drives, e.g. [23] - [29]. In studies, the focus was on efficiency of a specified drive concept, at different operating points, but with less attention to its dynamics.

In this control concept (VV-concept), two aspects are in the forefront of interest. The first is achievable dynamics, as in this case we have two options to "speed up" the response: by changing the setting of the variable pump (for example, the angle of the swash-plate of the axial piston pump) and at the same time by changing the speed of the electric drive motor above the nominal speed characteristic for mains voltage frequency.

Another aspect is to achieve the best possible efficiency of the entire electric motor-pump drive unit. For both the electric motor and the pump, the value of the total efficiency of each component depends on the operating parameters. Thus, e.g. the value of the total efficiency of the variable pump depends on the operating speed of the pump, the height of the operating pressure and the setting of the variable pump (of course at a certain viscosity of the hydraulic fluid). Similarly applies to the efficiency of the electric motor. In the case that the maximum efficiency of the entire drive is at the forefront as a control strategy, the speed of the electric motor and the pump setting can be adjusted so that at each operating point, the total efficiency is always in the area of the highest values. Similarly, we can set a strategy for achieving the fastest system response. 
In the case of using a variable pump, a fourth concept can be used: the variable pump can be used as a constant pump, by setting it to the maximum flow quantity, or even to a smaller one. This variant corresponds in principle to the use of a constant pump, e.g. gear pumps, only in this case we use another type of pump, e.g. axial piston pump (APP), which has a higher efficiency than the gear pump. In the case of a speedcontrolled variable APP set to a constant maximum value, this concept could be termed VC-APP-concept.

\subsection{Comparison of dynamics and efficiencies}

To compare different drive concepts, the comparison criteria need to be chosen. The most sensible is to compare the efficiency. However, since all the drive concepts do not follow the pressure set-point the same way, it is necessary to compare the included control error the difference between the pressure set-point and the actual pressure. This can best be done by calculating the root mean squared error according Eq. (1), since it eliminates the influence of the sign of the error.

$$
R M S E=\sqrt{\frac{\sum_{i=1}^{n}\left(p^{*}(i)-p(i)\right)^{2}}{n}}
$$

\section{RMSE [bar] root mean square error}

$n \quad[-] \quad$ number of pressure measurements

$p^{*}(i) \quad[\mathrm{bar}]$ pressure set-point of $i^{\text {th }}$ measurement

$p(i) \quad[\mathrm{bar}] \ldots$ actual pressure of $i^{\text {th }}$ measurement
Because the pressure waveform is different, supplied hydraulic energy is also not the same for all concepts, so it makes sense to add the consumed electrical and supplied hydraulic energy to the list. A lot of information of the dynamics of each concept is hidden in overshoot and setup time of the step change. Overshoot is defined as the maximum excess of the desired value of; set-time as the time that elapses from the initiation until the actual value reaches and remains within $5 \%$ of the desired value. The comparison will include both parameters at a step change from 50 bars to 150 bars.

To increase ease of comparison, all the criteria will be combined using weighted average, which will result in a numeric score. All the criteria, including weights, are shown in Table 2.

The best scores in each category are indicated in Table 3. The percentages for all criteria are weighted, summed and displayed in the last column of Table 3.

The consumed electricity and the supplied hydraulic energy have been measured over 50 consecutive cycles, which improves the accuracy of the measurements, as a cycle lasts for only $5 \mathrm{~s}$. The average yield was calculated as the quotient between the produced and consumed energy. Both form of energies quoted in Table 4 refer to one cycle. RMSE was calculated for the entire cycle and only sinusoidal change $(3 \mathrm{~s}$ to $5 \mathrm{~s})$. For the second step, settling time and overshoot were calculated. A close-up view of step changes of all the concepts is presented in Figure 9.

Table 2: Weights and criteria for comparing different drive concepts

\begin{tabular}{|l|c|c|c|c|c|c|c|}
\hline Category & \multicolumn{3}{|c|}{ Energy } & \multicolumn{3}{c|}{ Dynamics } \\
\hline Category weight & \multicolumn{3}{|c|}{$60 \%$} & & \multicolumn{2}{c|}{$40 \%$} \\
\hline \multirow{2}{*}{\begin{tabular}{l} 
Criterion \\
\cline { 2 - 8 } \\
Average \\
efficiency
\end{tabular}} & $\begin{array}{c}\text { Consumed } \\
\text { electricity }\end{array}$ & $\begin{array}{c}\text { Supplied } \\
\text { hydraulic } \\
\text { energy }\end{array}$ & $\begin{array}{c}\text { Total } \\
\text { RMSE }\end{array}$ & Sine RMSE & $\begin{array}{c}\text { Settling } \\
\text { time }\end{array}$ & Overshoot \\
\hline $\begin{array}{l}\text { Weights inside } \\
\text { category }\end{array}$ & $50 \%$ & $30 \%$ & $20 \%$ & $60 \%$ & $20 \%$ & $10 \%$ & $10 \%$ \\
\hline Final weights & $30 \%$ & $18 \%$ & $12 \%$ & $24 \%$ & $8 \%$ & $4 \%$ & $4 \%$ \\
\hline
\end{tabular}

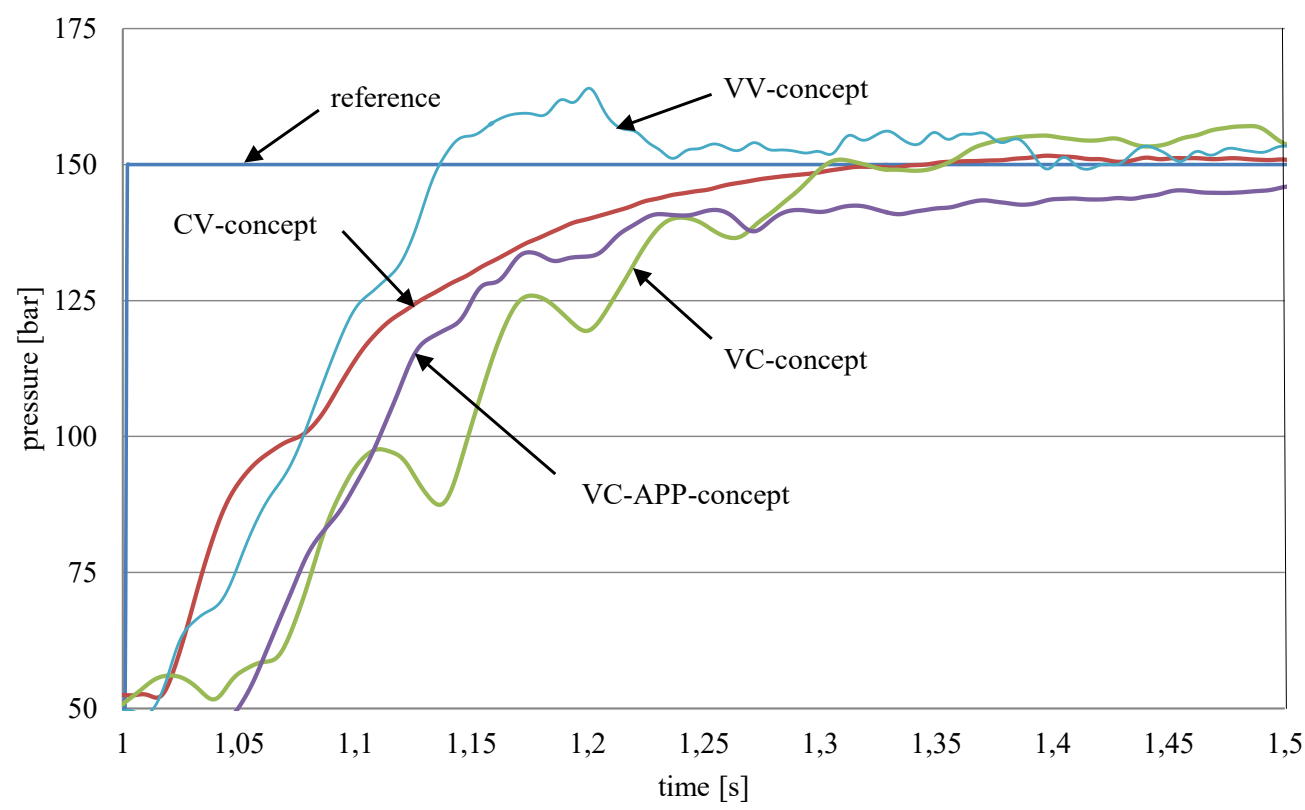

Figure 9: Comparison of step responses (from 50 bars to 150 bars) for different drive concepts 
Table 3: Measurement results of dynamics of different drive concepts

\begin{tabular}{|c|c|c|c|c|c|c|c|c|}
\hline Concept & $\begin{array}{c}\text { Average } \\
\text { efficiency }\end{array}$ & $\begin{array}{c}\text { Consumed } \\
\text { electricity } \\
{[\mathrm{kJ}]}\end{array}$ & $\begin{array}{c}\text { Supplied } \\
\text { hydraulic } \\
\text { energy } \\
{[\mathrm{kJ}]}\end{array}$ & $\begin{array}{c}\text { Total } \\
\text { RMSE } \\
{[\text { bar] }}\end{array}$ & $\begin{array}{c}\text { Sine } \\
\text { RMSE } \\
{[\mathrm{bar}]}\end{array}$ & $\begin{array}{c}\text { Settling } \\
\text { time } \\
{[\mathrm{s}]}\end{array}$ & $\begin{array}{c}\text { Over-shoot } \\
{[\mathrm{bar}]}\end{array}$ & Total \\
\hline CV-concept & $57,7 \%$ & 46,2 & 26,7 & 12,55 & 8,10 & 0,22 & 1,63 & $94,0 \%$ \\
\hline VC-concept & $56,9 \%$ & 45,4 & 25,8 & 21,22 & 14,42 & 0,28 & 7,07 & $79,7 \%$ \\
\hline VC-APP-concept & $57,5 \%$ & 46,0 & 26,5 & 19,79 & 12,56 & 0,36 & 0 & $83,1 \%$ \\
\hline VV-concept & $53,6 \%$ & 47,5 & 25,5 & 14,49 & 4,45 & 0,13 & 14,00 & $89,3 \%$ \\
\hline
\end{tabular}

Based on the average efficiency all the drive concepts perform similarly. The least efficient was the VV-concept with $\mathrm{PID}^{2}$-controller. The smaller average efficiency is due to non-optimal setting of the pump setting, and the unneeded acceleration and braking of the rotating parts. Although the desired pressures for all the concepts are the same, the produced hydraulic energy differs throughout different concepts, due to different control strategies. Concepts with lower dynamics produced less hydraulic power.

The ability to trace the desired profile is higher when using a variable displacement pump. RMSE is there more than 3-times lower. The dynamics of the systems are similar; VV-concept, which has for one-third the shortest settling time times with little higher overshoot. We were surprised that the dynamics (short settling time) of the drive concepts using a variable displacement pump were approximately 3-times higher, compared to those using a constant pump, whereas the literature states approximately 4-times higher dynamics. The case for this difference could be noise on the pressure signal, which prevented us from attenuating the controller parameters further.

\section{CONCLUSION}

Using a constant speed electric motor and variable pump (CV-concept) is the concept with a fairly high dynamic but a lower overall efficiency, (when also considering the electric motor efficiency at the pump's operating point), and less robust than a constant pump and variable speed drive (VC-concept).

VC-concept was asserted mainly due to good efficiency and a wide operating range [31]. It also excels at lower operating costs and a consecutively smaller effect on the environment. Lower operating costs and higher efficiency come mainly from the more efficient connection of the motor to the electrical grid via a variable-frequency drive controller. However, VC-concept also has one major drawback: a slow system response that occurs due to the moments of inertia of the rotating parts (motor rotor and rotary parts of the pump). The response of CV-concept is up to 5 times faster than the response of VC-concept [30] but both responses are good enough for most hydraulic applications.

If we look for the highest efficiency of the entire drive train at high responsiveness, the third concept (VVconcept) is promising drive concept. The biggest drawback of VV-concept is the highest purchase price amongst all the concepts because a variable frequency drive controller and a variable displacement pump are needed, where the variable displacement pump is the more expensive component of the required components. Additionally, is also necessary to pay attention to the hydraulic fluid cleanliness level and, of course, to know the values of the efficiencies of each component within the entire field regarding all operating parameters.

A principal comparison of the characteristics of each type of drive design concept is summarized in Table 4.

One of the disadvantages of the speed variable drive concepts, based on the use of an asynhronous) electric motor, is motor acceleration and deceleration for short pressure bursts. If a valve opens for 1 second, for example, the motor starts to accelerate to increase pressure and, after 1 second, has to decelerate again as the pressure is too high because the valve has closed again.

Every acceleration and deceleration using asynchronous electromotors results in higher current, which yields higher copper losses, where energy from decelerating rotating masses can be regenerated when using a state-of-the-art variable frequency drive controller. It is easily avoidable by adding a hydraulic accumulator to the hydraulic circuit, which smooths short pressure bursts and aids the motor and pump in their battles with rapid pressure changes.

From the drive component point of view, instead of usage of a frequency controlled asynhronous motor, a much better variant represents the usage of a speedcontrolled electric servo motor. Due to its smaller inertia, its reponsiveness is much better. This was also the reason why the VV-concept did not show even better dynamics than was achieved with the currently used "slow" asynchronous electric motor.

On the signal side, in respect to the control concept, the further improvement in regard to the energy efficiency is the implementation of an advanced control strategy, e.g. the usage of the s.c. $\eta$-drive concept or maximum efficiency drive concept, which is based on the VVconcept [31].

The heart of the $\eta$-drive concept is a maximum efficiency controller. The maximum efficiency controller controls the pump's displacement and rotational speed of the asynchronous motor using the variable frequency drive controller.

The maximum efficiency controller is based on a combination of a Look-up Table and a classic PID controller. The PID-controller is used to control the displacement of the axial piston pump. The advantages of using a PID-controller for displacement control are elimination of steady state error, fast response to rapid pressure changes and the ability to track pressure when the rotational speed of the motor is changing to the optimum. [32] 
Table 4: Considered variable electrohydraulic supply concepts in comparison

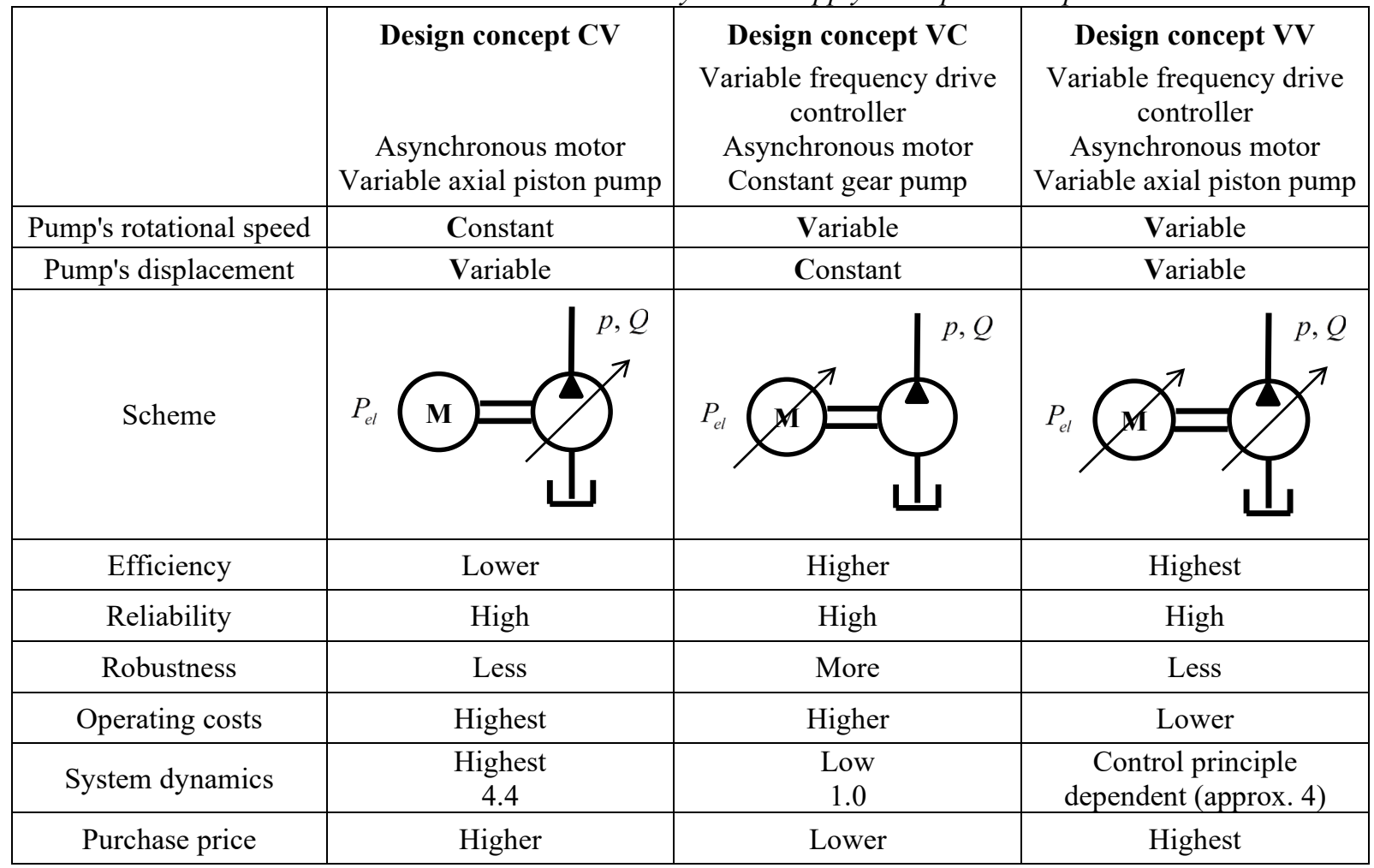

The next limitation when implementing the variable drive concept is at those operating points where the best efficiencies are achieved at pump settings close to $100 \%$. A Look-up Table that reports the best rotational speed at which a pump setting of higher than $100 \%$ would be needed to reach the pressure set-point. This error can arise due to fluid changes, temperature changes, wear or Lookup Table smoothing during calculation. To avoid this limitation, a feedforward loop for rotational speed should be added to increase rotational speed further if the desired pressure set-point cannot be reached with a $100 \%$ pump setting.

Further improvement can be made for machines with cyclic operational cycles, where the pressure cycle or load demands are repeating throughout the machines' operations. The pressure changes in this case can be predicted in advance. Therefore, it would be reasonable to couple the maximum efficiency controller with the Model Predictive Controller (MPC), which has already proved to be very useful for machines with repeating operation cycles.

\section{REFERENCES}

[1] S. Helduser, "Improved Energy Efficiency in Plastic Injection Molding Machines", $8^{\text {th }}$ Scandinavian International Conference on Fluid Power, SICFP'03, Tampere, Finland, (2003)

[2] A. Helbig, "Injection Molding Machine with ElectricHydrostatic Drives", 3. International Fluid Power colloquium, Aachen, Volume I, pp. 67-81, (2002)

[3] H. Esders, "Elektrohydraulisches Load Sensing für Mobile Anwendungen" (in German), O+P Ölhydraulik und Pneumatik 36, Nr.8, (1994)
[4] D. Lovrec, M. Kastrevc, S. Ulaga, "Electro-hydraulic load sensing with a speed-controlled hydraulic supply system on forming-machines", The International Journal of Advanced Manufacturing Technology, Vol. 41, No. 11-12, pp. 1066-1075, doi: 10.1007/s00170-008-1553-y, (2009)

[5] W. Huang, L. Quan, J. Huang, "Flow Matching with combined control of the pump and the valves for the independent metering swing system of a hydraulic excavator", Proceedings of the Institution of Mechanical Engineers Part D Journal of Automobile Engineering, Vol. 232, Iss.10 (1):095440701772884, pp. 1310-1322, doi:10.1177/0954407017728848, (2017)

[6] Z. Quan, L. Gei, Z. Wei, Y.R. Li, "A survey of powertrain technologies for energy-efficient heavyduty machinery, Proceedings of the IEEE PP(99), DOI:10.1109/JPROC.2021.3051555, (2021)

[7] I. Rühlicke, "Elektrohydraulische Antriebssysteme mit drehzahlveränderbarer Pumpe," $\mathrm{PhD}$ Thesis, TU Dresden, (in German), (1997)

[8] T. Neubert, "Untersuchungen von drehzahlveraenderbaren Pumpen (Eng.: Research of speed controlled pumps)", PhD Thesis, TU Dresden, (2002)

[9] R. Bonefeld, R., Ch. Lebert, "Adaptive pressure control using variable speed pump", $6^{\text {th }}$ International Fluid Power Conference Dresden, Workshop Proceedings, pp. 151-164, (2008)

[10] M. Ristic, M., "Conversant technology - New key aspects: Development of variable speed drives", $6^{\text {th }}$ 
International Fluid Power Conference, Conference Dresden, Proceedings, pp. 93-108, (2008)

[11] D. Lovrec, M. Kastrevc, "Modelling and simulating a controlled press-brake supply system”, International journal of simulation modelling, ISSN 1726-4529, Vol. 10, No. 3, pp. 133-144, doi: 10.2507/IJSIMM10(3)3.184, (2011)

[12] D. Lovrec, E. Detiček, F. Faber, "Electro hydraulic load-sensing with closed-loop controlled actuators theoretical background", Advances in production engineering \& management, ISSN 1854-6250, Vol. 4, No. 3, pp. 93-104. http://maja.unimb.si/files/APEM/APEM4-3_093-104.pdf, (2009)

[13] D. Lovrec, S. Ulaga, "Pressure control in hydraulic systems with variable or constant pumps?", Experimental techniques, ISSN 0732-8818. [Print ed.], Mar./Apr. 2007, Vol. 31, No. 2, pp. 33-41. http://dx.doi.org/10.1111/j.1747-1567.2007.00146.x, (2007)

[14] A. H., Sayed, "Fundamentals of Adaptive Filtering", John Wiley \& Sons, NY, p. 1168, (2003)

[15] D. Lovrec, F. Faber, "Electrohydraulic pressure control by a self-adjusting proportional derivative controller", Experimental techniques, ISSN 07328818. [Print ed.], May/June 2006, Vol. 30, No. 3, pp. 57-63. 1567.2006.00044.x, (2006)

[16] D. Lovrec, E. Detiček, "Improvement of the statical behaviour of pressure controlled axial piston pumps", Strojniški vestnik, ISSN 0039-2480, 2009, Vol. 55, No. 12, pp. 766-774, http://www.svjme.eu/scripts/download.php?file=/data/upload/2009/ SV-12-09/5_2009_069_Lovrec_zl_p766_774.pdf, (2009)

[17] M, Xu, B. Jin, G. Chen, J. Ni, "Speed-Control of Energy Regulation Based Variable-Speed Electrohydraulic Drive", Journal of Mechanical Engineering, Vol. 59, No. 7-8, pp. 433-442, doi:10.5545/sv-jme.2012.91, (2013)

[18] F.J.T.E. Ferreira, J. Fong, A. De Almeida, "Ecoanalysis of variable-speed drives for flow regulation in pumping systems", IEEE Transactions on Industrial Electronics, Vol. 58, No. 6, pp. $2117-$ 2125, (2011)

[19] W. Wang, B. Wang, “An energy-saving control strategy with load sensing for electro-hydraulic servo systems", Journal of Mechanical Engineering, Vol.62, No 12, pp. 709-716, doi:10.5545/svjme.2016.3685, (2016)

[20] J. Huang, Z. Zan, L. Quan, Y. Lan, "Characteristics of delivery pressure in the axial piston pump with combination of variable displacement and variable speed", Proceedings of the Institution of Mechanical Engineers, Part I: Journal of Systems and Control Engineering, Vol. 229, No. 7, pp. 573-586, (2015)

[21] T. Tašner, K. Les, V. Tič, D. Lovrec, "Energy efficiency of different electrohydraulic drives", $9^{\text {th }}$
International Fluid Power Conference, RWTH University, IFAS, pp.14-25, (2014)

[22] M. Man, F. Ding, C. Ding, S. Liu, S. "Study of an Energy Regeneration System with Accumulator for Hydraulic Impulse Testing Equipment", Journal of Mechanical Engineering, Vol. 61, No. 3, pp. 196206, doi:10.5545/sv-jme.2014.2138, (2015)

[23] E. Detiček, M. Kastrevc, "Design of Lyapunov based nonlinear position control of electrohydraulic servo systems", Journal of Mechanical Engineering, Vol. 62, No. 3, 163-170, doi: 10.5545/sv-jme.2015.2921, (2016)

[24] T. Žilić, J. Kasać, M. Essert, B. Novaković, Ž. Šitum, "Performance Comparison of Different Control Algorithms for Robot Manipulators", Strojarstvo Journal for the theory and application in mechanical engineering, Vol. 54, No. 5, pp. 399-407, (2012)

[25] H. Zupan, N. Herakovič, M. Starbek, J. Kušar, "Hybrid algorithm based on priority rules for simulation of workshop production", International journal of simulation modelling, ISSN 1726-4529, Vol. 15, No. 1, pp. 29-41, doi: 10.2507/IJSIMM15(1)3.319, (2016)

[26] J.F. Wang, W.L. Kang, J.L. Zhao, K.Y. Chu, "A simulation approach to the process planning problem using a modified particle swarm optimization", Advances in Production Engineering \& Management, Vol. 11, No. 2, pp. 77-92, http://dx.doi.org/10.14743/apem2016.2.211, (2016)

[27] T. Tašner, V. Tič, D. Lovrec, "Advanced control concepts suitable for energy efficient hydraulic systems", SIMULTECH 2013, $3^{\text {rd }}$ International Conference on Simulation and Modeling Methodologies, Technologies and Applications, Reykjavík, pp. 3-11, (2013)

[28] I. Petrović, T. Pavlic, A. Čikić, "The approach to stability determination of single axis positioning regulation for the model of TTT manipulator", Technical gazette, Vol. 21, No. 5, pp.1041-1046, (2014)

[29] B. Mohd, A. Mohd, K.A. Danapalasingam, A.R. Husain, "Design and optimization of backstepping controller for an under actuated autonomous Quadrotor unmanned aerial vehicle", Transaction of FAMENA, Vol. 38, No. 3, pp. 27-44, (2014)

[30] P. Casoli, N. Pompini, L. Riccò, "Simulation of an Excavator Hydraulic System Using Nonlinear Mathematical Models", Journal of Mechanical Engineering, Vol. 61, No. 10, pp. 583-593 doi:10.5545/sv-jme.2015.2570, (2015)

[31] D. Lovrec, V. Tič, T. Tašner, "Simulation-aided determination of an efficiency field as a basis for maximum efficiency-controller design", International journal of simulation modelling, ISSN 1726-4529, Vol. 14, No. 4, pp. 669-682, doi: 10.2507/IJSIMM14(4)9.324, (2015) 
[32] D. Lovrec, T. Tašner, V. Tič, "Dynamic behaviour of different hydraulic drive concepts - comparison and limits", International journal of simulation modelling, ISSN 1726-4529, Sep. 2017, Vol. 16, No. 3, pp. 448-457, (2017)

\section{Hidraulični pogonski sistemi sa kontrolom brzine za teške mašine}

Darko Lovrec $^{1 *}$, Vito Tič ${ }^{1}$

${ }^{1}$ Mašinski fakultet, Univerzitet u Mariboru, Maribor (Slovenija)

$U$ radu se razmatraju elektrohidraulični promenljivi sistemi napajanja u različitim konceptima projektovanja. U prvom planu diskusije su koncepti dizajna sa elektromotorom sa konstantnom $i$ brzinom kontrolisanom u kombinaciji sa konstantnim $i$ varijabilnim pumpama, implementiranim u okviru različitih strategija upravljanja.

Ključne reči: Hidraulični sistem napajanja, Promenljivi protok pumpe, Koncepti upravljanja 